\title{
Influence of Soy Protein Isolate on Gelatin-based Edible Film Properties
}

\author{
Iryanti Fatyasari Nata ${ }^{1, *}$, Chairul Irawan $^{1}$, Lazuardi Ramadhan $^{1}$ and Muhammad Rizky Ramadhani ${ }^{1}$ \\ ${ }^{1}$ Chemical Engineering Department, Lambung Mangkurat University, 70714 Banjarbaru, Indonesia
}

\begin{abstract}
Gelatin is a biopolymer that can be obtained from the partial hydrolysis of collagen skin tissue of chicken leg. This study aims to utilize gelatin of chicken leg skin in combination with soy protein isolate (SPI) as raw material for edible film production. The experiment was initiated by extracting gelatin and edible film was prepared by mixtures of SPI in ethanol solution and gelatin solution (containing $1 \%$ chitosan, w/v) with different weight ratio for SPI : gelatin $(1: 1,1: 2,1: 3,1: 4$, and $1: 5)$ then heated at $70{ }^{\circ} \mathrm{C}$ for $45 \mathrm{~min}$ and added $10 \%$ glycerol. Furthermore printed and dried in oven for $24 \mathrm{~h}$ at $60^{\circ} \mathrm{C}$. The yield of preparation of gelatin from chicken leg skin was obtained about $40.3 \%$. Higher concentration of gelatin in solution gives a transparent color and smooth surface of edible film. Base on mechanical properties analysis, the composition of 1:3 has the best result of tensile strength and elongation at break about 4.80 $\mathrm{MPa}$ and $113.37 \%$, respectively. The antibacterial activity test showed low antibacterial activity with a $0.3 \mathrm{~cm}$ inhibit zone.
\end{abstract}

\section{Introduction}

The skin of chicken leg is composed of a dense connective tissue rich in collagen. The utilization of collagen particles by hydrolysis will produce gelatin [1, 2]. Gelatin is widely used as a stabilizer, gelling agent, binder, thickeners, emulsifiers, adhesives and edible food wrappers [3]. Gelatin in Indonesia is imported from Europe and America, the utilization of gelatin application in the field of food about $60 \%$, it mean the production of gelatin will be increased in line with increasing of population. The production of gelatin is commonly from cows by $33 \%$ and $27 \%$ gelatin derived from pigs [4], so that gelatin is potential alternative material to be developed which is made from chicken leg skin, considering chicken production in Indonesia is abundant. Gelatin is material which can be reversibly changed from the sol form to the gel, swells or expands in cold water and is capable of forming a film [5]. Commonly, gelatin is used as raw material for edible film for food packaging. In addition, the chicken leg skin will be useful where only as a waste of chicken utilization. The advantage of using edible film is to extend the shelf life of the product and not to pollute the environment because the edible film can be eaten.

Previous studies have reported the utilization of edible film from soya protein isolate [6], gelatin [7, 8], and combination of gelatin, protein isolate and materials which have antibacterial activity $[9,10]$. However, there has been little discussion about characterization of edible film from combination of soy protein isolate (SPI) and gelatin which produce from chicken leg skin. It is necessary to develop gelatin production made from chicken leg skin for making edible film and expected to overcome the problem of food decay due to the activity of Staphylococcus aureus bacteria [11].

This study was focus on preparation of edible films in terms of comparison of SPI and gelatin concentration as a raw material that has the ability to kill bacteria. The aim of this study was characterized the morphological structure of edible film in terms of increasing the concentration of gelatin in the present of SPI through the scanning electron microscope (SEM) test, evaluating the optimum weight composition ratio of SPI:gelatin for edible film production. The characterization and analysis of mechanical properties such as tensile strength, elongation, and antibacterial activity of the edible film were also evaluated.

\section{Materials and Method}

\subsection{Materials}

Natrium hydroxide $(\mathrm{NaOH})$, sulfuric acid $\left(\mathrm{H}_{2} \mathrm{SO}_{4}\right)$, citric acid $\left(\mathrm{C}_{6} \mathrm{H}_{8} \mathrm{O}_{7}\right)$, hydrochloric acid $(\mathrm{HCl})$, ethanol $\left(\mathrm{CH}_{3} \mathrm{COOH}\right)$, and glycerol $\left(\mathrm{C}_{3} \mathrm{H}_{8} \mathrm{O}_{3}\right)$ were obtain from Sigma-Aldrich and Acros. All other chemicals were analytical grade used without further purification. Chicken leg skin and soy protein isolate were collected

Corresponding author: ifnata@unlam.ac.id 
from traditional local market.

\subsection{Preparation of gelatin from chicken leg skin}

Chicken legs skin was washed with water flow then drained. The skin $(300 \mathrm{~g})$ was immersed in $1.5 \%$ acetic acid solution, the skin and solution ratio 1: $8(\mathrm{w} / \mathrm{v})$ for 3 days. After that, it washed thoroughly with dionized (DI) water until filtrate of solution reach to neutral $\mathrm{pH}$. The residue of sample was extracted in $65 \%$ ethanol in a three-neck flask with ratio about 1: $2(\mathrm{w} / \mathrm{v})$ for $1 \mathrm{~h}$. After extraction was completed, added distilled water in to mixture with ratio $1: 1(\mathrm{v} / \mathrm{v})$ and keep at $64{ }^{\circ} \mathrm{C}$ for $1 \mathrm{~h}$, followed by washing and filtering. The extracted product was dried in an oven at $70{ }^{\circ} \mathrm{C}$ and blended and sieved to obtain gelatin powder.

\subsection{Edible film preparation}

Edible film was prepared by combination of SPI and gelatin in weight ratio is $1: 1,1: 2,1: 3,1: 4$ and 1: 5 . The gelatin was dissolved in $1 \% \mathrm{w} / \mathrm{v}$ chitosan in acetic acid. Soy protein isolate dissolved with ethanol and each solution was stirred until homogeneous. After that the solution was mixed together and added $10 \% \mathrm{v} / \mathrm{v}$ glycerol with stirring rate $90 \mathrm{rpm}$ at $70{ }^{\circ} \mathrm{C}$ for $45 \mathrm{~min}$. The mixture was poured into a Teflon $(\mathrm{d}=20 \mathrm{~cm})$. The edible film was formed after sample was dried at $55^{\circ} \mathrm{C}$ for $24 \mathrm{~h}$.

\subsection{Characterization}

Scanning electron microscope (SEM) images of the samples were obtained by scanning electron microscope (JEOL, JSM-6500LV). The tensile strength of edible films was tested by using Lloyd's universal Testing Instrument machine. The elongation is expressed as the maximum force applied to the film.

Staphylococcus aureus grown in LB medium was employed to examine the antibacterial effect of edible film Staphylococcus aureus grown overnight at $37{ }^{\circ} \mathrm{C}$ were harvested by centrifugation and washed twice with pH 6.5 and $0.9 \% \mathrm{NaCl}$ solution. Staphylococcus aureus solution was uniformly plated on LB nutrient agar plates. A piece of edible film was thick of diameter about $1 \mathrm{~cm}$ which placed on the agar plates. The plates were incubated at $37{ }^{\circ} \mathrm{C}$ for overnight. The antibacterial activity of the samples was measured based on the width of the clear zone formed around the samples.

\section{Results and Discussion}

Gelatin was produced by soaking and extraction of chicken leg skin. When it is soaked in $1.5 \%$ acetic acid, it is possible to interact between collagen fibrils with acetic acid and result in collagen protein will be swelling. During heating process, the collagen protein will be extracted into gelatin. Yield of gelatin produced from the skin of chicken leg about $40.3 \%$. The chicken leg skin as raw material is shown in Fig.1 (a) and gelatin product can be seen in Fig.1 (b).

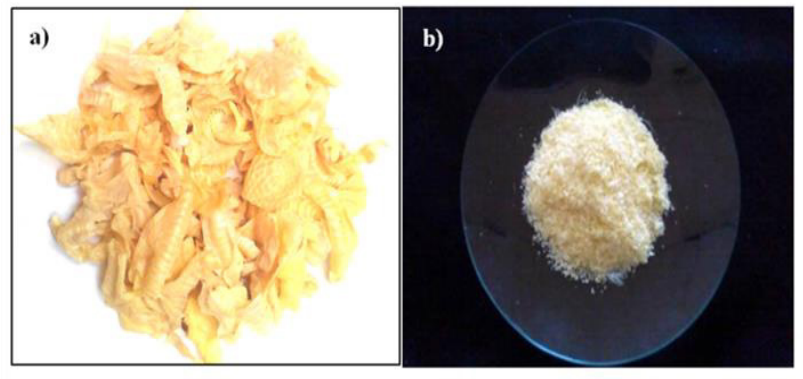

Fig. 1. Chicken leg skin (a) and gelatin product from chicken leg skin (b).

\subsection{Edible film production}

The edible films resulting from variation weight ratio of SPI and gelatin can be seen in Fig. 2. Visualization test is done by placing an image below edible film. In Fig. 2 there is a clear for edible film which weight ratio 1:1 has brightest/white color; it is because the composition of SPI and gelatin is same and SPI is difficult to dissolve in the solution and not completely dissolve, so that the color of edible film produced was cloudy.

The variation of 1:5 has light transparent color; image below the edible film could be seen clearly. By increasing concentration of gelatin will give transparent color, it is because the high concentration of gelatin facilitates SPI dissolves in the solution.
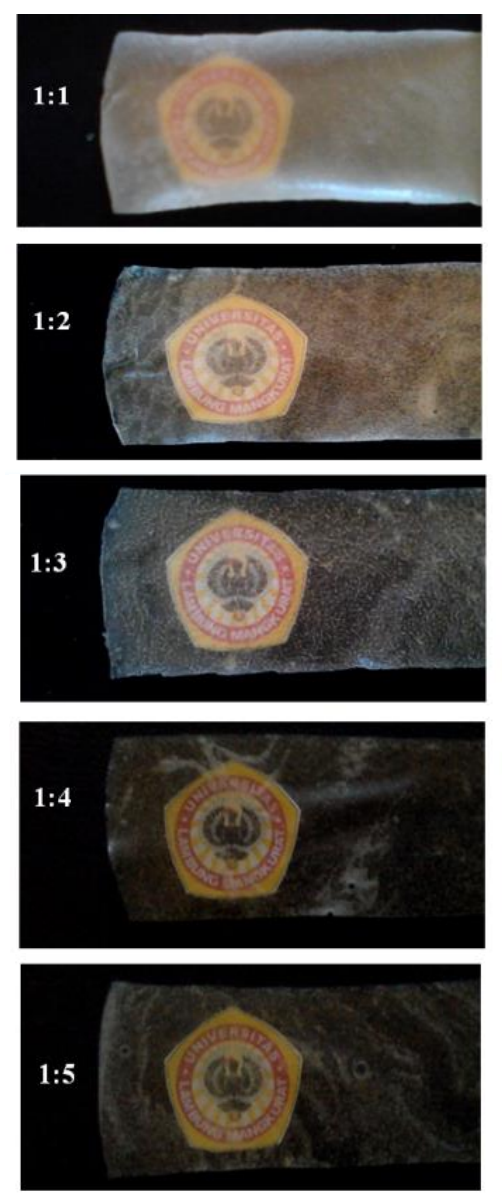

Fig. 2. Edible film product from different weight ratio of SPI : gelatin for $1: 1 ; 1: 2 ; 1: 3 ; 1: 4$; and 1:5. 
Prior studies that it has noted that the effect of gelatin concentration on edible film product is become transparent. High concentration of gelatin will make the edible film more transparent, homogeneous and not easily broken [12]. In addition, when the mixture of gelatin and SPI under heating condition, the gelatin is form triple helix collagen structure which able to dissolve SPI and the surface product of edible film becomes smoother [13].

\subsection{Edible film characterization}

The surface of edible film was observed by SEM, it is shown in Fig.3. It is apparent from the weight combination ratio of 1:1 shows the number of aggregates on the surface and its dense of SPI.
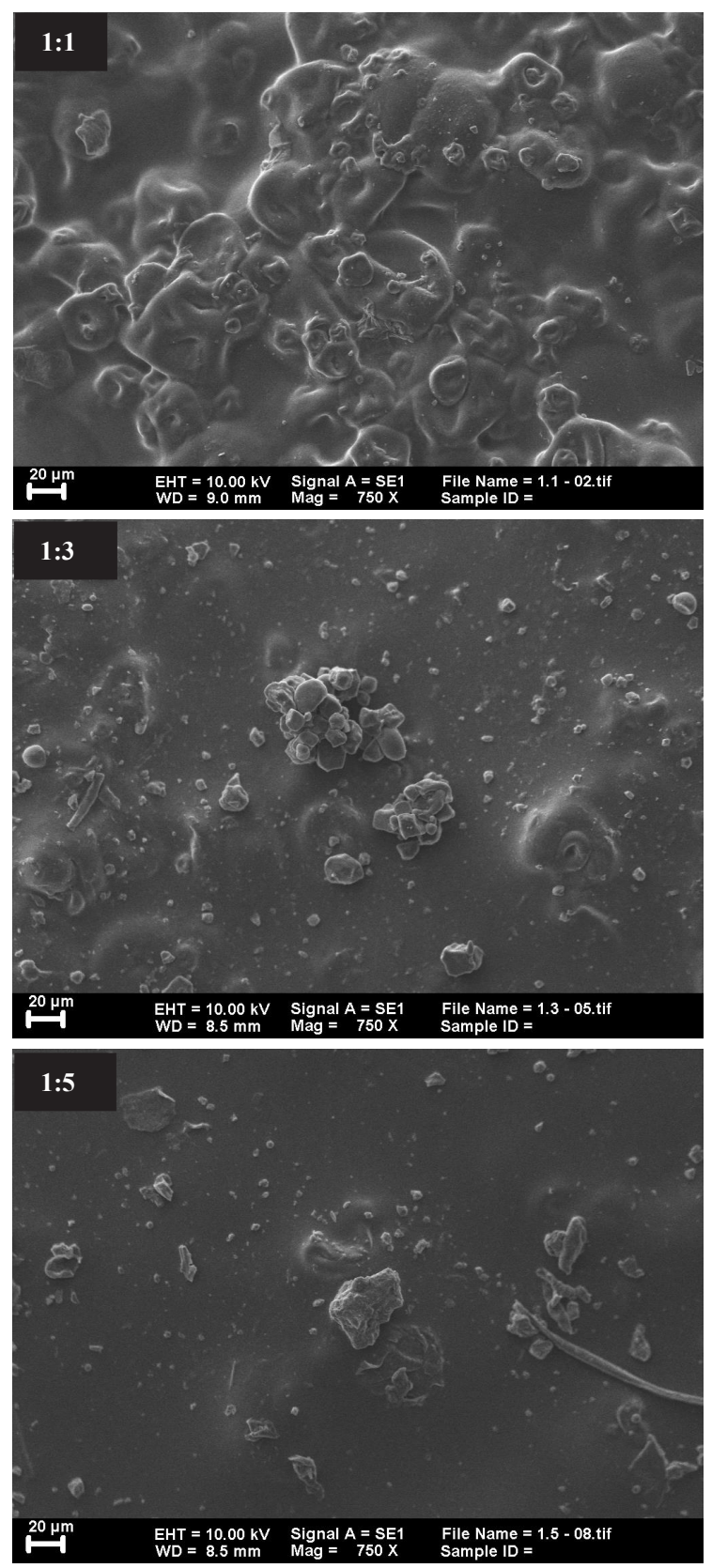

Fig. 3. SEM images of edible film with weight combination ratio of SPI : gelatin for $1: 1 ; 1: 3$; and 1:5.
Due to limited solvent in the mixture, SIP is not dissolving completely. Effects of this, color of edible film becomes white (Fig. 2). From fig. 3 for composition of 1:3, SEM resulted in the lowest concentration of SPI. It means more SPI was dissolved.

In order to understand how the mechanical properties of edible film, the tensile test was performed to determine the tensile strength of samples and also measure maximum force required to break the sample. This test useful for application of edible film with high tensile strength will be able to protect the product packaged from environment [14]. The result of edible film tensile strength is presented in Fig. 4.

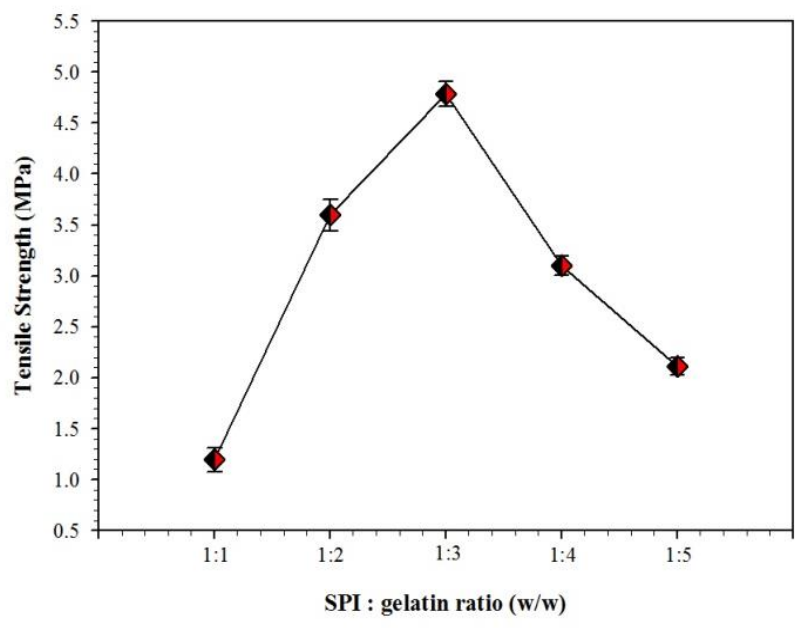

Fig. 4. Tensile strength of edible film product from different weight ratio of SPI : gelatin for $1: 1 ; 1: 2 ; 1: 3 ; 1: 4$; and 1:5.

The tensile strength test for weight combination ratio $1: 1 ; 1: 2 ; 1: 3 ; 1: 4$; and $1: 5$ were $1.20 \mathrm{MPa} ; 3.60$ $\mathrm{MPa}$; 4.80 MPa; 3.10 MPa; and 2.11 MPa, respectively. The most striking result to emerge from the data is that the value of tensile strength test increases with the increasing gelatin concentration, it is due to an increase concentration of collagen in gelatin [13]. However the increasing tensile strength only up to weight ratio of $1: 3$, for composition 1:4 and 1:5 ratio, the tensile strength were decreased. The decreasing tensile test in this composition because of reduction of intermolecular interactions so that the matrix formed will be less and also excess of gelatin composition have effects to polymerization is not maximum. The tensile strength value of an edible film is determined by the structure of the woven form and the protein content in gelatin containing collagen [15]. In addition, the tensile strength of edible film will decrease which made from soy protein isolate because there is not all SPI particles participate in the matrix film formation [16]. Gelatin has better mechanical properties than that SPI because gelatin is more flexible and elastic [17]. The results of this study show that edible film with weight composition 1:3 has highest tensile strength value about 4.80 $\mathrm{MPa}$. Another research was prepared edible film using SPI and gelatin in weight ratio has tensile strength about 1.50 Mpa [12]. 
A strong relationship between tensile strength and elongation has been known for edible film. Elongation test for edible film is to determine the resistance of cracking and to know the flexing endurance as well as to show the maximum film length change when getting the tensile force until the film is broken compared to initial length. The elongation test can be seen in Fig. 5.

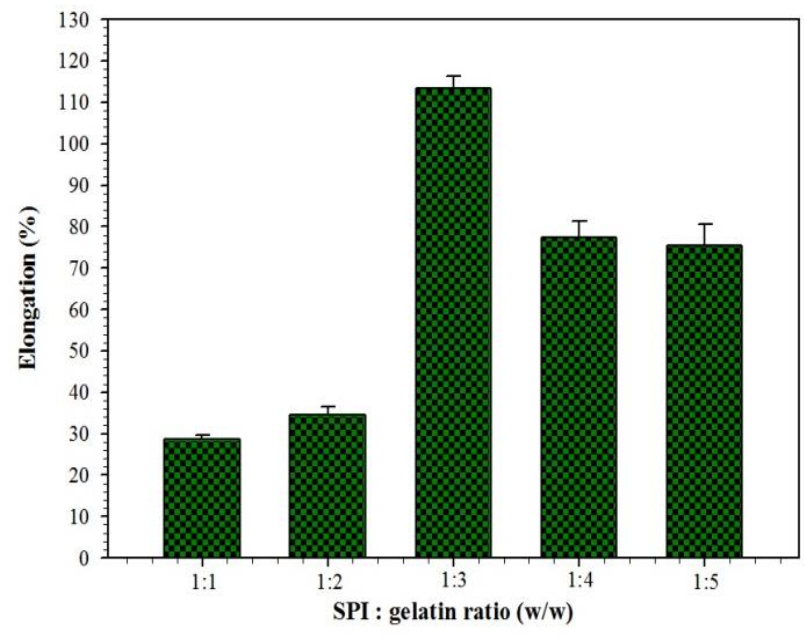

Fig. 5. Elongation of edible film product from different weight ratio of SPI : gelatin for $1: 1 ; 1: 2 ; 1: 3 ; 1: 4$; and 1:5.

Fig. 5 shows same trend with tensile strength profile (Fig. 4) which elongation of edible film was increased up to $113.37 \%$ for weight composition of $1: 3$. When the gelatin concentration was increased for composition 1:4 and 1:5, the elongation was decreased to $75.52 \%$. The decreasing value of edible film depend on structure of intermolecular the matrix, when excess of gelatin concentration, the polymerization between collagen and SPI are not optimum. The standard elongation value for edible film should more than $50 \%$ [3]. This research product as edible film is quite good mechanical properties for elongation about $113.37 \%$. On comparison for mechanical properties of commercial wrapping plastic have value of tensile strength and elongation about $0.86 \mathrm{MPa}$ and $4.8 \%$, respectively.

The edible film was tested for antibacterial activity against the growth of Staphylococcus aureus bacteria by the agar diffusion method. Fig. 6 is shown the antibacterial activity for each composition. The antibacterial activity of edible film is shown by a clear zone around the film. If the halo zone does not appear it is assumed that there is no drag zone in the film. The result of the test is presented in Fig. 6, weight ratio of 1:1 was gives antibacterial effects with a clear zone area about $0.3 \mathrm{~cm}$. Edible film composition of 1:2 showed only a little have antibacterial effect. For composition of $1: 3 ; 1: 4$; and 1:5 have no inhibit zone, this is because SPI and gelatin has no oligopeptide chain, which is suspected to have antimicrobial properties due to the presence of amino groups in the chain. Characteristics of hydrophobic amino acids will make the peptide chain become positively charged so it can enter into the bacterial membrane causing interaction between peptide chains of gelatin with bacteria surface [18].
The existence of chitosan in the edible film have effects to the antimicrobial activity, chitosan will form a polymer membrane on the surface of Staphylococcus aureus cells that will inhibit the nutrients into the cell. This is due to the presence of amine groups in chitosan which have a cationic charge which can bind the feeding source of bacteria such as alginate, pectin, protein, and inorganic polyelectrolytes such as polyphosphates. The chitosan antibacterial activity increases with increasing chitosan molecular weight. Organisms will be inhibited when contacted directly with the active side of the chitosan film [19]. In other hand, only chitosan gel or solution form exhibits optimal biological properties, because chitosan in these form the amine group will be easily protonated [11].

In this case, there is different concentration of gelatin containing chitosan which effect to active agent switching that acts as antibacterial. The weigth composition ratio $1: 1$ has more chitosan contain in the matrix of edible film and shown antimicrobial effect.

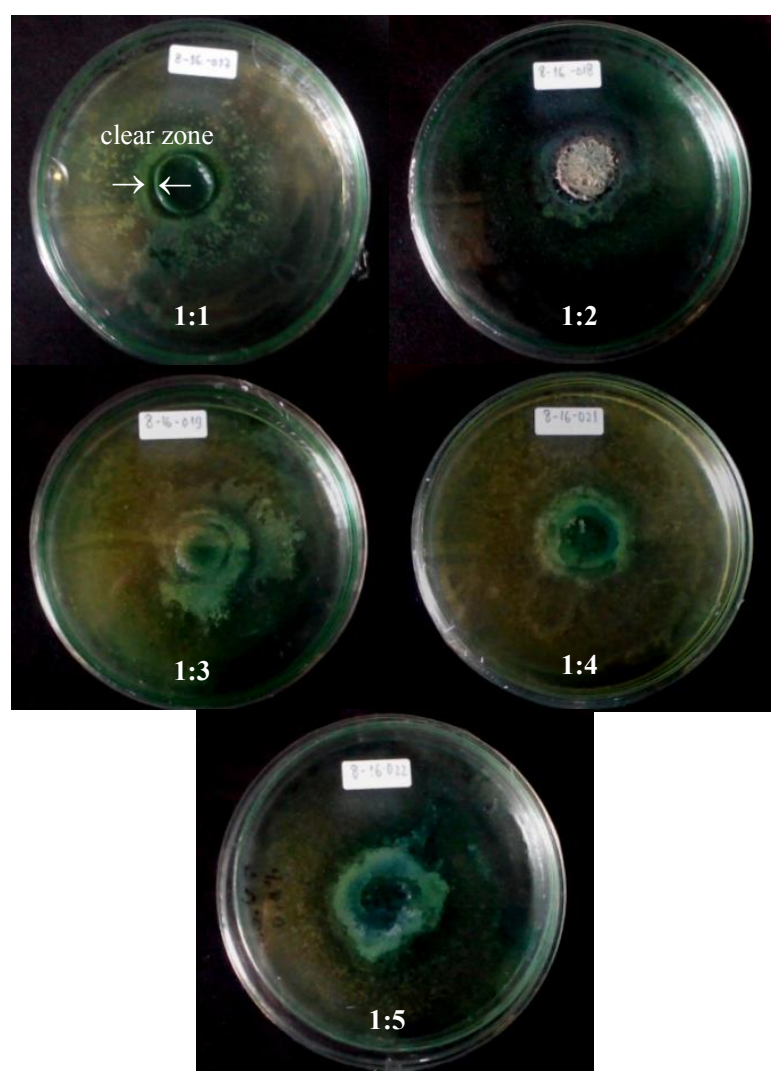

Fig. 6. Antibacterial activity with Staphylococcus aureus for edible film product from different weight ratio of SPI : gelatin for $1: 1 ; 1: 2 ; 1: 3 ; 1: 4$; and $1: 5$.

\section{Conclusions}

Edible film can be synthesized by combination weight ratio of soy protein isolate and gelatin from chicken leg skin. The chicken leg skin as a alternative raw material for gelatin production. The optimum value base on mechanical properties of edible film in the weight ratio of SPI : gelatin is 1:3. The value of tensile strength and 
elongation at break of sample is possible to make it become media for coating or wrapping food.

The authors are grateful for the financial support from Ministry of Research, Technology and Higher Education, Republic of Indonesia, which provided Research Grand (PKM-PE) 2016.

\section{References}

1. H. Tavakolipour, World J. of Fish and Marine Sci. 3, 1 (2011)

2. I. M. S. Negara and I. N. Simpen, J. Chem. 8, 1 (2014)

3. J. M. Krochta and C. D. Muller-Johnson, CRC Press LCC, Florida (2002)

4. V. S. Wiyono, J. Halal LPPOM-MUI, 36 (2001)

5. R. a. H. G. Schrieber, "Gelatine handbook : Theory and industrial practice," (2007)

6. D. S. Liyanage, M. Tillekeratne and S. Hewage, J. Natn. Sci. Foundation Sri Lanka 29 (2001)

7. M. C. Gómez-Guillén, M. Ihl, V. Bifani, A. Silva and P. Montero, Food Hydrocolloids 21, 7 (2007)

8. S. Zhang, Y. Wang, J. L. Herring and J. H. Oh, J. of Food Sci. 72, 9 (2007)

9. A. A. Al-Hassan and M. H. Norziah, Food Hydrocolloids 26, 1 (2012)

10. N. M. Sarbon, F. Badii and N. K. Howell, Food Hydrocolloids 45 (2015)

11. P. Fernandez-Saiz, J. M. Lagaron, P. HernandezMuñoz and M. J. Ocio, Int. J. of Food Microbiol. 124, 1 (2008)

12. M. Hasdar, Y. Erwanto and S. Triatmojo, , 35, 3 (2011)

13. H. Chambi and C. Grosso, Food Research Int. 39, 4 (2006)

14. D. T. H. Suryaningrum, J. Basmal, dan Nurochmawati, Penelitian Perikanan Indonesia 11, 4 (2005)

15. I. Arvanitoyannis, E. Psomiadou, A. Nakayama, S. Aiba and N. Yamamoto, Food Chem. 60, 4 (1997)

16. N. Cao, Y. Fu and J. He, Food Hydrocolloids 21, 7 (2007)

17. K. Y. Lee, J. Shim and H. G. Lee, Carbo. Polym, 56, 2 (2004)

18. D. Mardian, L. Atmaja and M. Najib, Thesis, Sepuluh November Institute of Technology, (2011).

19. J. Gómez-Estaca, López de Lacey, A., LópezCaballero, M. E., Gómez-Guillén, M. C., \& Montero, P., Food Microbiol, 27 (2010) 